ment and only partially restores the sulcal changes a chronic anorexic state has been suggested to cause persisting morphological changes in the brain. ${ }^{13}$

Although bulimia nervosa was originally described as an ominous variant of anorexia nervosa, ${ }^{1+}$ the short term outcome in the two disorders seems similar ${ }^{15}$ - but because bulimia nervosa is an episodic condition the short term findings may be misleading. An observation that mortality in bulimia nervosa was as high as in anorexia nervosa gives some support for a pessimistic view of the disorder, but until longer term follow up of persisting eating disturbance is reported this view remains unsubstantiated.?

GEORGE PATTON

Lecturer in Psychiatry,

Academic Department of Psychiatry,

Royal Free Hospital,

London NW3 2QG
1 Gull $W^{\prime} W$. Anorexia nervosa (apepsia hysterica, anorexia hysterica). Transactions of the Clinical Society of London 1874:7:22

Kay DW K. Anorexia nervosa: a study in prognosis. Proceedings of the Royal Society of Medicine 1953;46:669-74.

3 Williams E. Anorexia nervosa: a somatic disorder. Br Med f 1958;ii: 190-5.

4 Hsu LKG, Crisp AH, Harding H. Outcome of anorexia nervosa. L ancet 1979;i:61-5.

Morgan $\mathrm{HG}$, Purgold $\mathrm{J}$, Welhourne J. Management and outcome in anorexia nervosa: a standardized prognostic study, Br f Psychiatry 1983:143:282-97.

6 Hall A Slim E. Hawker F, Selmond $C$ Anorexia nervos: long-term outcome in 50 female patients. Brf Pswchiatry 1984;145:407-13.

patients. Br f Psychiatry 1984;145:407-13.
Patton GC. Mortafity in eating disorders. Psychol Med 1988;18:947-51.

8 Theander S. Outcome and prognosis in anorexia nervosa and bulimia: some results of a previous Theander S. Outcome and prognosis in anorexia nervosa and bulimia: some results of a previous
investigation, compared with those of a Swedish long-term study. I Psychiatr Res 1985;19: investigation,

493-508.
Treasure JL, Russell GFM, Fogelman I, Murby B. Reversible bone loss in anorexia nervosa. Br.Med I 1987;295:474-5

10 Szmukler GI, Brown SW, Parsons V, Darby A. Premature loss of bone in chronic anorexia nervosa. Br Med f 1985;290:26-7.

11 Artmann H, Grau H, Adelman M, Schleiffer R. Reversible and non-reversible enlargement of cerebrospinal fluid spaces in anorexia nervosa. Neuroradiology 1985;27:103-12.

2 Lankenau H. Swigar ME, Bhimani S, Luchins S, Quinlon DM. Cranial CT scans in eating disorder patients and controls. Compr Psychiuty 1985;26:136-47.

13 Dolan RJ, Mitchell J, Wakeling A. Structural brain changes in patients with anorexia nervosa. Psychol Med 1988:18:349-53.

14 Russell G. Bulimia nervosa: an ominous variant of anorexia nervosa. Psychol Med 1979;9:429-48.

15 Hsu LKG, Holder D. Bulimia nervosa: treatment and short-term outcome. Psychol Med 1986;16:65-70.

\title{
Cardiac surgery in the elderly
}

\section{Can produce substantial benefits at the price of a moderately increased risk}

Twenty years ago a leading article in the $B M \mathcal{F}$ noted that surgical treatment for elderly patients with cardiac valvular disease was "not at present feasible," and as recently as 1979 the benefit of coronary artery bypass grafting in the elderly was questioned. ${ }^{2}$ Since then, however, growing numbers of progressively older patients have had aortic or mitral valve replacement and coronary artery bypass grafting..$^{3-7}$ In Edinburgh $10 \%$ of all adult open cardiac surgery is performed in patients aged over 70. Many of these operations are, however, attended by a higher risk of death or complications ${ }^{489}$ and a longer, more expensive hospital stay. ${ }^{10}$ Do the results justify these greater physical and financial costs?

The operative mortality in coronary artery grafting has fallen progressively ${ }^{11}$ and in the United States is now $0.7 \%$ for those aged under $65,2 \%$ for those aged 65 to 75 , and $5 \%$ for those aged over 75.5 Recent data from Britain are based on smaller numbers, ${ }^{312}$ but the Papworth group's report of no early deaths in 117 operations in those aged over 65 is exceptional. ${ }^{3}$ These figures become even more impressive when it is considered that age is not the sole risk factor in these patients. When compared with younger patients more of the elderly have multivessel or mainstem stenoses, unstable symptoms, impaired left ventricular function, and, perhaps most importantly, disease of other systems, as over half the hospital deaths relate to non-cardiac conditions. ${ }^{+13-15}$ Postoperative complications are also more common than in younger patients,${ }^{8}$ with stroke, the complication most likely to carry prolonged sequelae, occurring in $2-5 \% .^{59} 16$

Balanced against these risks is the fact that symptoms, commonly disabling, are greatly diminished, 5715 perhaps even more so than in younger patients. ${ }^{5}$ Patients need fewer tablets after their operations, and from experience and anecdote they have a happier and better life after coronary surgery. The long term survival after coronary artery bypass grafting in most patients aged over 65 exceeds that of patients treated medically ${ }^{17}$ and equals that of the general population, with $95 \%$ surviving one year and $89 \%$ eight years after operation. ${ }^{3}$

Replacement of the aortic or mitral valves in the elderly has a higher operative mortality, with an overall rate of $5 \%$ for those aged over 65 in one series in Britain, ${ }^{3}$ rising to $8 \%$ in those aged over $70,{ }^{9}$ and up to $30 \%$ in those aged over $80 .^{6}$ Coronary artery disease often coexists, and this increases mortality, ${ }^{18}$ but concurrent coronary artery bypass grafting carries little additional risk to those aged over 70 having aortic valve replacement. ${ }^{9}$ Serious late complications of valve replacement relate to congestive cardiac failure, coronary artery disease, thromboembolism, and the problems of anticoagulation, ${ }^{19}$ but long term survival after these operations in patients aged over 65 is good, with $88 \%$ surviving one year and $74 \%$ surviving five years compared with expected survivals in these age groups of $96 \%$ and $80 \%$ respectively. ${ }^{3}$ Moreover, appreciable, prolonged relief of symptoms commonly follows valve surgery, up to $92 \%$ of survivors returning to an improved functional state. ${ }^{19}$

Clearly, therefore, elderly patients, whose alternative without surgery is often poorly controlled symptoms and early death, ${ }^{1720}$ benefit from coronary artery bypass grafting and valve replacement at the expense of a modestly increased risk. Application of standard selection criteria coupled with careful assessment of each person's risk and capacity to benefit can maintain the high standards already achieved.

But can the newer, alternative treatments with balloon dilatation techniques match these standards? Currently, for most elderly patients, they cannot. Balloon angioplasty of the coronary artery can reduce symptoms in those fewer elderly patients with limited coronary artery disease, ${ }^{21}$ and balloon dilatation of the mitral valve (T R D Shaw, British Cardiac Society spring meeting, 1989) and perhaps the aortic valve ${ }^{22}$ may be a worthwhile alternative to medical treatment in patients unfit for surgery, but none of these procedures is likely to reduce greatly the number of elderly patients requiring operations.

As the proportion of people aged over 65 continues to rise $\mathrm{e}^{23}$ and their incidence of cardiovascular disease fails to fall appreciably the present demand for surgery is likely at least to be maintained. Most patients are prepared to meet the increased physical cost of these operations, and, arguably, they have already met the higher financial cost in their long working lives. We can only hope that our changing health 
system accords as much value to the results as do the patients, their relatives, and their doctors.

ANDREW T ELDER

Research Fellow,

Department of Cardiology, Western General Hospital,

Edinburgh EH4 2XU

Consultant Cardiothoracic Surgeon,

E W J CAMERON

Royal Infirmary,

Edinburgh EH3 9YW

1 Anonymous. Systolic murmurs in the elderly [Editorial]. Br Med $\mathcal{F} 1968$;iv:530-1.

2 Kirklin JW, Kouchoukos NT, Blackstone EH, Oberman A. Research related to surgical treatment of coronary artery disease. Circulation 1979;60:1613-8.

Livesey S, Caine N, Spiegelhalter DJ, English TAH, Wallwork J. Cardiac surgery for patients aged 65 years and older: a long term survival analysis. Br Heart f 1988;60:480-4.

4 Gersh BJ, Kronmal RA, Frye RL, et al. Coronary arteriography and coronary artery bypass surgery: morbidity and mortality in patients aged 65 vears or older. A report from the Coronary surgery: morbidity and mortality in patients aged

5 Loop FD, Lytle BW, Cosgrove DM, et al. Coronary artery bypass graft surgery in the elderly. Cleve Clin F Med 1988;55:23-34

6 Edmunds LH, Stephenson L.W, Edie RN, Ratcliffe MB. Open-heart surgery in octogenarians. N Engl Y. Med 1988:319:131-6.

7 Naunheim KS, Kern MJ, McBride LR, et al. Coronary artery bypass surgery in patients aged 80 years or older. A $m$ f Cardiol 1987;59:804-7.
8 Montague NT, Kouchoukos NT, Wilson TAS, et al. Morbidity and mortality of coronary bypass grafting in patients 70 vears of age and older. Ann Thorac Surg 1985;39:552-7.

9 Arom KV Nicoloff DM, Lindsay WG, Northrup WF, Kersten TE Should valve replacement and related procedures be performed in elderly patients? Ann Thorac Surg 1984;38:466-70.

10 Roberts AJ, Woodhall DD, Conti CR, et al. Mortality, morbidity, and cost-accounting related to coronary artery bypass graft surgery in the elderly. Ann Thorac Surg 1985;39:426-32.

11 Gersh BJ. Coronary revascularisation in the elderly. Current Opinion in Cardiology 1987;2:1002-7.

12 Morgan JM, Gray HH, Clague JC, Gibson DG. Coronary artery surgery in the elderly is effective in the relief of angina [Abstract]. Br Heart 7 1988;59:603-4.

13 Rose DM, Gelbfish J, Jacobowitz. IJ, et al. Analysis of morbidity and mortality in patients 70 vears of age and over undergoing isolated coronary artery bypass surgery. A $m$ Hearl 7 1985;110:341-6. 14 Ennabli K, Pelletier LC. Morbidity and mortality of coronary artery surgery after the age of 70 vears. Ann Thorac Surg 1986;42:197-200.

15 Acinapura AJ, Rose DM, Cunningham JN, Jacobowitz IJ, Kramer MD, Zisbrod Z. Coronary artery bypass in septuagenerians: Analysis of mortality and morbidity. Circulation 1988;78 (suppl 1):179-84

16 Gardner TJ, Horneffer PJ, Manolio TA. Stroke following coronary artery bypass grafting: a ten year study. Ann Thorac Surg 1985;40:574-81.

17 Gersh BJ, Kronmal RA, Schaff HV, et al. Comparison of coronary artery bypass surgery and medical therapy in patients 65 years of age or older. $N$ Engl f Med 1985;313:217-24.

18 Rahimtoola SH, Cheitlin MD, Hutter AM. Valvular and congenital heart disease in the elderly. f Am Coll Cardiol 1987;10 (suppl A) 60-62A.

19 Jamieson WRE, Dooner J, Munro AI, et al. Cardiac valve replacement in the elderly: a review of 320 consecutive cases. Circulation 1981:64 (suppl II):177-83.

20 Rapaport E. Natural history of aortic and mitral valve disease. Am f Cardiol 1975;35:221-7.

21 Simpfendorfer C, Raymond R, Schraider J, et al. Early and long-term results of percutaneous transluminal coronary angioplasty in patients 70 years of age and older with angina pectoris. Am f Cardiol 1988;62:959-61.

22 Block PC. Aortic valvuloplasty-a valid alternative? $N$ Engl $\mathcal{M}$ Med 1988;319:169-71

23 Craig J. The growth of the elderly population. Population Trends 1983;32:28-33.

\section{Treating migraine}

\section{Try stress reduction and simple analgesia first}

More than five million people suffer from migraine in the United Kingdom, ' and most do not consult their doctor about it. Many will have learnt about their headaches from relatives - up to $70 \%$ of sufferers have a family history of migraine. ${ }^{2}$ Ways of dealing with attacks differ: some will ignore them, and others will take a simple analgesic and retreat to a quiet, darkened room. Some sufferers need sleep to recover.

If patients consult their general practitioner about migraine the reason for this should be sought. If it is their first headache they may be worried about a possible brain tumour. A sympathetic hearing and examination followed by reassurance about the benign origin of their headaches is usually all that is required, although some will benefit from advice on using simple analgesics. Inquiries into the psychological and social background of patients presenting with headaches should be made: more headaches or worse headaches sometimes indicate anxiety or a depressive disorder.

Little scientific evidence exists for the benefit of biofeedback, hypnotherapy, and acupuncture, but some patients prefer these to treatment with drugs. Techniques of managing stress, whatever form they take, are probably helpful. Dietary manipulation is contentious; some patients will have noticed that certain foods provoke their migraine and will have learnt to avoid them. Cheese, pickled herring, red wine, and chocolate are all believed to provoke migraine as they contain substrates for monoamine oxidase-tyramine and phenylethylamine, ${ }^{3}$ although not all researchers share the view. ${ }^{+}$ Some migraine sufferers, who may have a disordered carbohydrate metabolism, ${ }^{5}$ notice that missing a meal brings on an attack, and they should take regular, small meals.

Another hypothesis links food allergy and migraine. A double blind trial of an oligo-antigenic diet found that $98 \%$ of 88 children with severe migraine recovered on such a diet, ${ }^{6}$ and another study found that sodium cromoglycate was helpful. ${ }^{7}$ More work is needed before exclusion diets can be recommended. ${ }^{89}$

Treatment has traditionally been divided into managing acute attacks and prophylactic treatment, but this distinction may be artificial. For treating individual headaches simple analgesics usually suffice - for example, aspirin $900 \mathrm{mg}$ four hourly or paracetamol $1000 \mathrm{mg} .{ }^{8}$ Proprietary compounds, usually containing either of these drugs as the main ingredient, may be more helpful in some patients. Soluble or effervescent forms may be more palatable and their absorption faster from the migrainous gut. If nausea and vomiting are a problem metoclopramide or domperidone, which have antiemetic and gastric emptying effects, should be given at the first sign of a migraine attack, preferably before the analgesic (and so should be prescribed separately). If drugs given orally fail suppositories may be used; injections are usually left for emergency management by doctors. Domperidone $(30 \mathrm{mg}$ ) may abort attacks if given at the onset of prodromal symptoms up to 48 hours before the actual attack. ${ }^{10}$

Ergot has been used since 1894 for headache and its effectiveness in migraine has been accepted for many years. " Recently its side effects - nausea, muscle cramps, and peripheral gangrene with overdose - have made it less popular. Long term use of ergotamine may also lead to permanent headache and its withdrawal to rebound headache, ${ }^{12}$ which usually requires admission to hospital for supervised withdrawal of the drug. Nevertheless, ergotamine remains a useful drug for a few patients with infrequent, severe attacks of migraine. As its oral absorption is poor ${ }^{13}$ it should be given by suppository or inhalation. Not more than $12 \mathrm{mg}$ ergotamine should be given in a week and it should be stopped if headaches become more frequent. Combinations of ergotamine and propranolol or methysergide should be avoided. ${ }^{1+}$

If aspirin and paracetamol fail to control headaches nonsteroidal anti-inflammatory drugs may work. Ibuprofen $400 \mathrm{mg}$, now available without prescription, is better than paracetamol 900 mg. ${ }^{15}$ Naproxen ${ }^{16}$ and mefenamic acid ${ }^{17}$ may also be considered. Naproxen may be the best treatment for menstrual migraine ${ }^{18}$ and should be started one week before the onset of menstruation.

Pharmacological prophylaxis is generally recommended when the severity of migraine interferes with normal lifewhen two attacks or more occur each month or when less frequent, severe headaches are resistant to usual treatment. 